\title{
The Ecology of Communicative Contact in English-Speaking Discourse
}

\author{
Victoria Samokhina \\ Department of English Philology, V.N. Karazin Kharkiv National University, Kharkiv, Ukraine \\ Olena Shpak \\ Department of English Philology, V.N. Karazin Kharkiv National University, Kharkiv, Ukraine \\ Valentyna Pasynok \\ School of Foreign Languages, V. N. Karazin Kharkiv National, Ukraine
}

\begin{abstract}
The article explores the ecological essence of English-speaking discourse as optimal ratio of phatic and informational content in contacts of addressants and addresees in different spheres of communication. Unison and dissonant contacts are distinguished as ecological and non-ecological communicative contacts. The set of standards and rules of verbal and non-verbal behavior in English society organizes and regulates communicative process. The type of situation and the addressee are leading factors on three stages of contact: establishing, maintaining and breaking. The findings are supported with the examples taken from the English discourse.
\end{abstract}

Index Terms - communicative contact, discourse, dissonant, ecological, unison

\section{INTRODUCTION}

An obvious trend in the development of modern linguistics is the shift from description of structural language units to the plane of analysis of their functioning: a person establishes contact with another person through their communicative activities in socio-cultural environment, which is the ecological basis of Homo Sapiens's existence. So, linguistic research focuses on the main subject of communication - Homo Contactum - the man in contact. When contacting, communicators can be attuned to either effective (constructive) interaction or ineffective (destructive), thus producing beneficial, ambivalent or destructive discourses (Stibbe, 2015). Ecological friendliness is manifested in the specifics of the ratio of individual creative intentions to the social context (Samokhina, Shpak 2019), which makes it favorable, that is promotes establishing sustainable relationships between humans themselves, and humans and nature as a whole (Ivchenko, 2021, p. 1080). The view of communication as ways, means and the condition of human survival, which ensures the preservation of its ecological system, justifies absolute purposefulness, motivation and regulation of communicative interaction.

Contemporary communication space increasingly demonstrates the incontinence of emotions in all spheres of human relations. The general decline in tolerance, increasing aggression, resentment, even in business and diplomacy discourses, leads to a deterioration of the climate of interpersonal communication (Shakhovskyi, 2015, p. 20-25). Modern ecolinguistics is characterized by a wide range of topics related to dysfunction of speech and speech behavior, the use of invective vocabulary, profanity, slang, etc. Therefore, the question of the effectiveness of language communication brings this science to the forefront of humanities research, as it puts forward a new system of evaluation of language units as those that are ecological, i.e. favourable for human existence, or non-ecological, unfavourable for his or her existence in the surrounding community. As there is a tendency to conduct comprehensive research in modern linguistics, the importance of the communicative category CONTACT for understanding the specifics of English communication in different types of discourse situations, both in terms of methodological issues (defining the informative and phatic functions in unison and dissonance contacts) and in terms of practical analysis (verbal and nonverbal means of establishing, maintaining and closing communicative contacts in various spheres of people's life), as well as addressing the study of this category from the standpoints of discourse analysis, functional and communicative approach, and ecolinguistics is considered relevant. The aim of the work is to identify verbal and nonverbal means of realization of the communicative category CONTACT, and to study the ecolinguistic features of communicative contacts in different types of English discourse.

\section{RESEARCH METHODOLOGY}

The study of communicative contact from the standpoint of functional-communicative linguistics, ecolinguistics and discourse analysis promotes new knowledge about the mechanisms of communication and the description of the means of contact phases in different types and situations of discourse. The focus of the work is the ecological essence of 
contacting in modern English discourse, and the aim is to expand the understanding of laws of interpersonal communication and ways to improve the effectiveness of interactions in social ecosystems by controlling verbal and nonverbal means. The functional-communicative approach to the study of speech phenomena analyses communication for functions: "functional" means aimed at the use of language in communication process, at studying functions of language units in interaction with the situational context, at revealing a purpose and role of a language unit in a specific communicative contact, thus seeking for ways and means to ensure its effectiveness; "communicative" involves communication as an activity, transmission of information, informing process, understanding and interpretation of what is said, and hence the phenomenon of information exchange (Samokhina, 2012, p. 15). Ecological analysis of discursively relevant and culturally specific linguistic units which act as means of contact contributes to the expansion of scientific knowledge about the ecology of communication in different types of discourse. The material of the research involved communicative fragments of the implementation of the communicative category CONTACT from English prose works, as well as scripts and subtitles for feature films.

\section{THEORETICAL BACKGROUND}

The phenomenon of contact is understood as a communicative category with anthropocentric properties - such as goals and functions, realized in the discursive interaction of the addressant and the addressee, taking into account their social roles, relationships and psychological state due to situational factors of the communication. A contact is established, maintained and closed between communicators who share a common language and culture.

Discourse is viewed as an inter-subjective thought-provoking communicative activity of people in a certain situation. D. Cameron (2015) notes that a better definition of discourse than "language over sentence" may be "language in action", i.e. the language used to do something and mean something, the language created and interpreted in the context of the real world (p. 172). Discourse is discrete in the sense of articulation; its largest unit is a communicative event which is in an inclusive relationship with the discourse; such a communicative event, in our opinion, is a contact. Each phase of a contact corresponds to a change in communicators' knowledge about specific properties and characteristics of the objects and situations under discussion, so the psychological state of communicators in the process of communicative contact is constantly changing and widely depends on the communicative strategy that speakers choose during their communication. Thus, logic and, at the same time, the ecologically correct choice of means and ways in discourse is ensured by the purpose of communication. Dialogic discourse reflects the communicative event of contact, in which partners verbally and non-verbally, by exchanging remarks and communicative roles in a particular situation through certain strategies and tactics seek to achieve the desired results. Cf .: "embedding is a part of our linguistic ability to speak of events at any remove in time and space from the situated present" (Goffman, 1981, p. 3), which fully fits into the principles of ecological communication.

Communicative categories are the most general and common in their content communicative concepts that contain the most essential communicative information. The communicative category CONTACT is a hyperdiscursive, culturally specific category regulating speakers' activity in the phases of establishing, maintaining and closing contacts. It is characterized by two-layer nature, as phatic and informational content is explicated in discourse, and by its bipolarity, i.e. communicative unison and communicative dissonance. The communicative category CONTACT is a set of norms and rules of speech behavior of communicators in status or personal relationships, which demonstrates the specifics of verbal and non-verbal means of expression, such as language patterns, etiquette formulas, utterances of greeting and farewell, humorous expressions and specific phraseology of maintaining contacts, ritualized indicators of consensus, confirmation etc. (Samokhina, Shpak 2019, p.15-18). The basis of the communicative category CONTACT is the concept "contact", which represents the idea of English-speaking people of the process of communication. The notion "contact" is a common activity of discourse subjects in starting communication with the aim of phatic and informational exchange. A contact as a mode of communication is a set of specific verbal and non-verbal utterances in various types of communicative situations: ordinary, non-ordinary, extraordinary. Contact is also influenced by a sphere of communication (institutional and non-institutional) and a configuration of speakers' roles (agent - agent, agent - client or family member, friend). Contact includes informational and phatic content and represents discursive strategies of harmonization or disharmonization. 


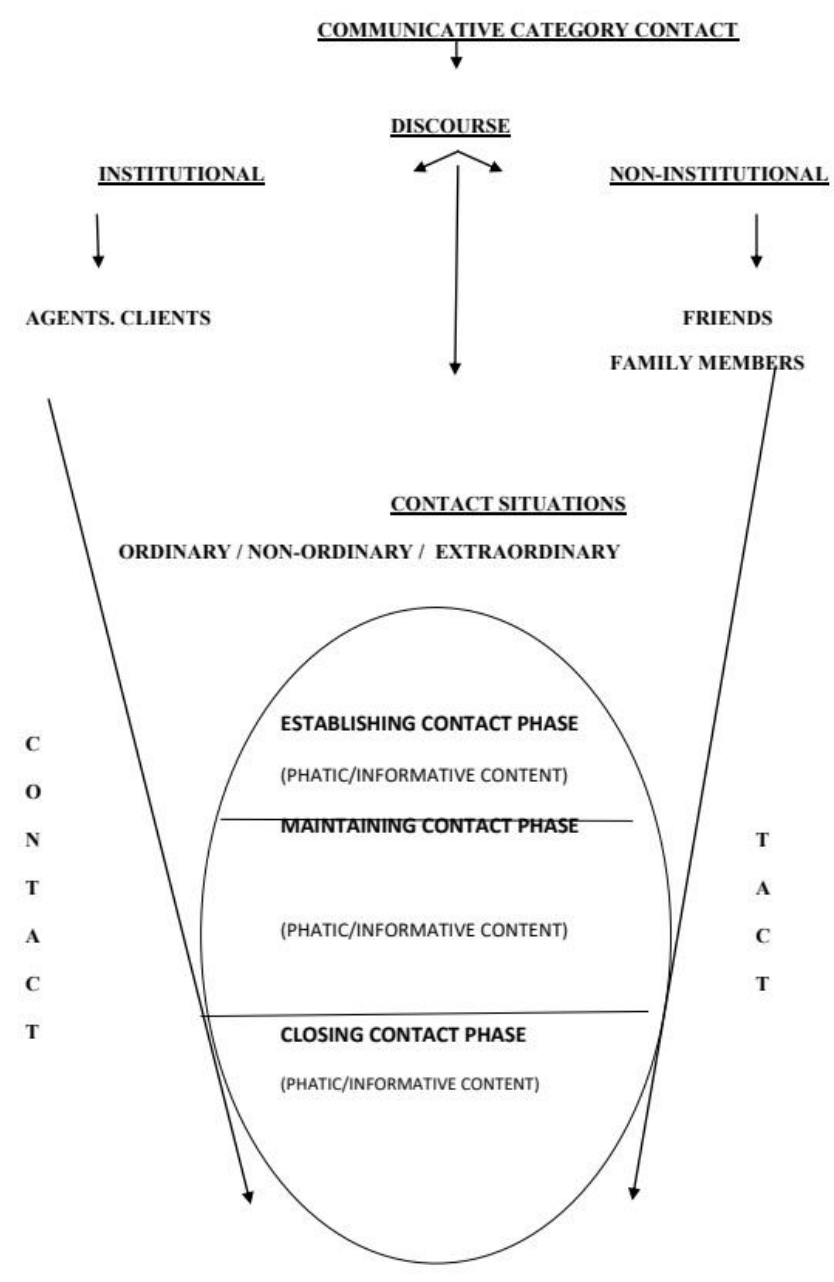

UNISON / DISSONANT CONTACT

Figure 1. Graphic presentation of the Communicative Category CONTACT

The specifics of the manifestation of the communicative category CONTACT in different linguistic cultures are different, so when coming into contact with another culture there is a dissonance of mentalities, worldviews and values. Contact process aimed at achieving a communicative goal is usually built in accordance with the principles and rules of the communicative code of a particular linguistic culture. Values and concepts of culture influence verbal and nonverbal norms of contact, which takes place in various spheres of social life. The value component is the leading aspect of the content of the category. While examining the value component of the communicative category CONTACT, it is easy to notice its ambivalence - the presence in its content of both positive and negative components, which follows from the semantics of the nominative unit contact. The Universal Dictionary of the English Language providing lexicalsemantic variants of the word "contact" clarifies the modality of communication: pleasant, friendly - "friendly communication, sympathy, rapport", which manifests the second meaning of "contact" as a consequence of the first one: ecological contact under favorable conditions, commitment of speakers to each other, maintenance of friendly relations, an established contact, i.e. cooperative communication, and also unpleasant, unfriendly - "hostile, unfriendly meeting, clash of interests, opinions, collision" (UDEL,1958, p. 232) - non-ecological communication in the conflict zone, which is accompanied by disorder, inconsistency, rupture and loss of contact in whole. Thus, based on the above mentioned definitions, the work highlights the unison ecological contact "plus-polarity" as a way of symbolic coordination of communicative activity - sincere recognition of achievements, views and positions of the partner, psychologically uncomplicated harmonious dialogue in which speakers sound in unison for conflict-free cooperative, coordinated interaction, and dissonant non-ecological contact "minus-polarity", characterized by inconsistency, which is manifested in remarks of the oppositional type in the contradictory pragmatic connection of disagreement, denial, refusal, aggression etc.

A unison contact is an example of ecological communication and is a prerequisite for the development of discourse. This is a harmonious way for speakers to communicate for the sake of conflict-free, cooperative and well-coordinated interaction. A dissonant way of contacting is a non-ecological way of communication, a communicative failure, which, 
due to situational factors or individual psychological attitudes of the subjects of discourse to one another, disharmony of their relations, manifests itself in the oppositional form of speech behavior and can lead to communication disorders.

National communicative culture is crucial for the effectiveness of communication, so the study of the cultural aspect of English-language communication, which shapes the ecological thinking of the British, is an important issue for ecolinguistics. It has been found that the communicative category CONTACT is closely connected with the communicative category POLITENESS, and, accordingly, is a set of norms and rules of speech behavior in Englishspeaking society, organizing and regulating the communicative process with the help of various means of expression. The content of this category includes such communicative prescriptions as restrained manner of communication while maintaining communicative contacts, observance of communicative imperatives and taboos, demonstration of the general culture of speech. This is a central nationally-specific communicative category, manifesting a system of ritualized strategies of communicative behavior aimed at harmonious, conflict-free communication and compliance with socially accepted norms in establishing, maintaining and closing interpersonal ecological contacts (Larina, 2009, p. 8).

Oksana Issers correlates such concepts as tactics and tact (Issers, 2013, p. 255). It has been investigated that the lexical unit contact has a connection with tact $[\boldsymbol{F}<\boldsymbol{L}$ tactus, pp. of tangere, to touch <IE base tag-, to touch, grasp > OE thaccian, to stroke] - "a delicate perception of the right thing to say or do without offending, skill in dealing with people" (WNWD, 1993, p. 1483) - the ability to communicate, delicate, tactful attitude to the interlocutor in order to prevent any offence or resentment. Thus, a unison contact demonstrates the implementation of the strategy of harmonization of relations through tactics based on the principles of politeness (tact, generosity, approval, modesty, consent and sympathy), which form not only the foundation of information and regulatory competence and communicative norm (Brown, Levinson, 1987), but also a national value of the British. Geoffrey Leech (1983) defined the Tact maxim, which reads: "Minimize the expression of beliefs which imply cost to others; maximize the expression of beliefs which imply benefit to others". The norms of contact, which are a clarification of ethical rules of conduct in communication, and good manners, the purpose of which is to inhibit aggression and create a social union, are rigidly enshrined in cultural ritualization. Anglo-Saxon culture perceives excessively emotional behavior without much of approval, with suspicion and embarrassment. Communicative attractiveness and non-impressiveness are the dominant features of English behavior (Larina, 2009, p. 50): "a Londoner takes it for granted that people with whom he comes into contact will treat him not only politely but also affably" (Ovchinnikov, 2008, pp. 434-436). Therefore, politeness and a tactful attitude towards the partner is the background of information and regulative competence, a communicative standard.

Non-verbal components of contact establishing are traditionally expressed in the form of a touch and a knock. A significant role in the communicative contact of English speakers is played by a kiss, especially in non-institutional discourse: Kissing has long played a part in greetings and farewells. The kiss has a complex history as a seal of trust, gesture of peace, a sacred touch, a Juda's-like portent of betrayal or disaster, and a magic charm, besides its simple uses as a token of greeting and affection - and its potential as something profane, invasive, outrageous (Hitchings, 2013 , p. 49). In general, contacts in non-institutional sphere, in addition to informative and meaningful content in interaction on everyday affairs, are close, personal communication events in the English family. They are mostly ecological in the full sense of the word, as they tend to reveal deep spiritual connection and mutual understanding of friends and family members. The English linguistic and cultural community is characterized by a certain closeness of family relations: the family is tenderness and home where a person can find a shelter from the aggressive world, it is a refuge in the stormy sea of life - "The family is a heaven in a heartless world" (English proverb).

\section{RESULTS AND DisCUSSION}

Contacts take place in various spheres of social life, in discursive social practices. The common communicativerelevant meaning is seen as an ecological criterion of belonging of a specific communicative situation to a certain type of discourse and is crucial for its understanding. The structure of the communicative situation includes the typological stratification of the communicative event, the way of communication, the organization of contact process, the topology and chronology of the communicative event, the socio-situational characteristics of the participants, their socio-status relations and motivational-target orientation components. The totality of all lingual and extra-lingual components characterizes communication in a certain type of discourse. A formal addressing in institutional discourse, for example, raises certain expectations, adjusts to a formal style of communication. It is different from non-institutional discourse, in which it would be natural to have a family greeting. Therefore, professional communication is characterized by ecologically specific contacts, due to the social functions of partners, regulated by both content and form, and determined by standards and social norms. The ritualization of reporting with the use of weapons in the army is illustrated in this communicative event of contact, which consists of three phases and presents an ordinary situation in military discourse:

(1) Private John Marston Moore, United States Marine Corps Reserve, had practiced his maneuver, but he had never before rendered the rifle salute to a real officer: He marched through the door identified by a stenciled sign as that of MAJOR H. B. HUMPHREY, USMC, BATTALION COMMANDER, with his piece at right shoulder arms, determined to do so the best of his ability. 
He stopped eighteen inches from the Major's desk, with his heels together and his feet turned out equally and forming an angle of 45 degrees. He then moved his left hand smartly to the small of the stock, forearm horizontal, palm of the hand down, the first joint of his left forefinger touching the cocking piece of his Springfield Model 1903A4 rifle.

"Sir," he barked, looking at Major Humphrey. "Private Moore, J.M., reporting to the battalion commander as ordered."

... Major Humphrey touched his eye lid with his right hand, fingers together and straight, palm down.

The salute had been returned (Griffin, 1991, p. 53).

Marine Corps Reserve Private Moore in the office of Battalion Commander Major Humphrey reports on his arrival at his new service place. In the initial phase, he uses ritual kinetic components of communication - movements with a gun, prosodic non-verbal component - he barked, stereotypical military Sir and the military formula of self-representation in the function of contact establishing (informative component of contact). Maintenance and closing of contact by the addressee takes the form of ritual salute in response. This contact manifests ecological norms of unison contact in military discourse. The functional-communicative approach made it possible to find out that military discourse demonstrates maximum informativeness, is mostly presented in three phases; the function of contact-establishing utterances is performed by orders, self-presentations, messages, etc.; the contact-supporting phase is presented by utterances in the function of messages and explanations; orders and order-execution reporting are the leading informative contact-closing functions regardless of the type of situation. Manifestation of contact in military discourse displays status focusing, objectified in specialized military etiquette formulae of orders and reports, and such non-verbal means as gestures of saluting, motions with rifles etc.

The ecological essence of institutional discourse is manifested in a formal and standard style of communication, which implies a high level of formality, a great number of clichés, a strict necessity to comply with norms. Habitual masks are a set of standard phrases, gestures as well as smiles that allow interlocutors to hide true emotions and attitudes towards each other. In general, it is believed that optimism and pleasantness in communication in all kinds of English-language institutional discourse is the norm of speech behavior (Have an excellent day! I'll love to see you again soon! We must get together).

Stereotypical speech cliché are manifested as means of implementing speech etiquette, represented by a system of clichéd expressions and stereotypical phrases, which are used to establish, maintain and close speech contacts for the effectiveness of communication. The set of rules for the choice and use of stereotypical speech means determines the environmental specificity of institutional contacts. However, informational content increases from minimum to maximum under complicated conditions of communication. It has been observed that in extraordinary situations, such ones, which go beyond everyday practice and involve emergencies or risk, the distance between communicators and a set of precedent texts and discursive formulas that emphasize the idea of representation in institutional discourse and oblige partners to communicate in a strict accordance with the norms of a particular society may be avoided, which does not necessarily make the interaction non-ecological. The decrease in ecology can occur due to changes in the ratio of phatic and informative content in favour of informativeness. In our opinion, the informativeness of a contact in institutional discourses increases because it presupposes a certain effectiveness and the desire to win (to make a profit, to consolidate power, to enforce an order etc.), which is achieved primarily through words, predominance of argumentation, rhetoric attack as a skill of reasoned influence on the addressee: Arguments, even when pursued in what we would regard as quite a civilized fashion, are warlike: "She attacked all my main points" (Hitchings, 2013, p. 34).

A combination of phatic and informational content is different in institutional and non-institutional types of discourse. Phatic and informational content is determined by the specificity of functions which means of contact perform. Noninstitutional spoken discourse demonstrates prevalence of phatic content and a focus on interpersonal relations, thus manifesting striving for consensus. A fully-extended ecological contact presents a development of initial phatic content into informative content, which objectifies a theme of conversation in a contact supporting phase. Closing contact is returning to phatic content as the theme has been already discussed or the discussion is over. A topic of conversation, the situation topic of the contact is another factor that reflects the realities of the current situation; its variety, the etiquette theme (greetings, farewells, thanks, etc.) is set by the socially regulated norms of speech design in a certain communicative event, as well as linguistic and cultural rules that exist in the form of expectations and implementation of which are required by society.

In contrast to the institutional, non-institutional discourse (personality-oriented and personal is understood as a conversational speech of informal interpersonal contacts, which does not include a strategic block and a current subject, which is necessary for effective communication in institutional discourse. The personal nature of contacts here is ecologically sound and is usually associated with deviations from current norms in society, ease, informality, a high degree of acquaintance, symmetrical social relations and so on, which is manifested in plain language with stylistically reduced etiquette, simple sentences, great amount of phraseology and family slang. Cf .: Harry: "We contact each other the normal way, text messages, phone calls" (Petrella, 2011, p. 46 ).

In the following example of ecological contact in an ordinary situation in the domestic sphere, we observe the expression of sincere feelings of the child and his father: 
(2) Children would come round from school, one of them would fling himself into Tom's arms with the cry "Daddy."

"Let's go down to decks today, son," he would say, kissing him. "There's big German vessel come in this morning with three funnels. You don't see them very often. And your Mom will have tea ready when we get back."... (Worth, 2002, p. 268).

In the phase of contact establishing, the father picks up his son in his arms (non-verbal component of contact), who happily exclaims "Daddy" (phatic component). The father maintains contact, informing the son about pleasant future plans (informative component of contact). Both the addressant and the addressee are set up to continue communicative and emotional contact and develop harmonious relationships.

An example of environmental contacts can be pleasant conversations on common subjects, so called small talks, the main purpose of which is to spend a nice time with an interlocutor, acquaintance or a stranger, staying in verbal contact with him or her. Small talks, as a linguistic phenomenon, are defined as speech events of ritualized form, characterized by predominance of socio-regulatory information, language game and aesthetic components (O'Connor, 2017). These requirements especially apply to women's communication: A lady should have sweetness in language... Her sober, quiet manners should not prelude a lively quickness of wit; and she should at all times present herself gracefully but also discreetly (Hitchings, 2013).

Ecological means of contact in non-institutional discourse are conventionalized elliptical expressive utterances, phraseology, colloquial expressions, rhyming, children's poems, adopted in a family discourse, or in the communication of friends, humorous greeting and farewell forms performing a function of emotionally-colored reaction to a meeting or parting, common for communication in a circle of close acquaintances and are peculiar only to conversational noninstitutional discourse. Non-verbal components of communication are of great importance here: gentle touches, kisses, tender intonation, etc. Communication in non-institutional discourse demonstrates creative approach to the choice of means and ways of contacting, sometimes non-verbal, as speakers understand each other almost without words.

The strategy of disharmony, which manifests a dissonant contact, on the contrary, is associated with non-parallel speech actions of the interlocutors, conflicting, rival speech behavior in discussion of the subjects of discourse. In situations of non-ecological contacts, communicative behavior goes behind speech norm, so the tactics that implement the strategy of disharmonization of relations are based on the violation of strategies of positive and negative politeness. A dissonant contact displays inconsistency, confrontation, aggression, neglect, lack of interest, verbal and nonverbal expression of negative attitude, categorical tone, raising or lowering the voice, speaking through teeth or sobbing. Other non-verbal manifestations of non-ecological contact include violation of distance, non-compliance with the rules of changing roles, inappropriate offensive gestures or facial expressions, which leads to a natural closing of contact, but to a gross violation of the ecological essence of contact, i.e. ineffective result of communication, quarrel, broken relations, etc. Thus, the consistency of the parameters of the subjects of discourse ensures the ecologically correct communication, while the inconsistency of the parameters of the interlocutors often leads to a violation of communication norms and loss of contact. The main role in initiating conversation is played by the addressant, so his or her responsibility for the ecology of the contact is essential. If both subjects of discourse tend to develop an ecological contact, i.e. are on the path of rapprochement, then in their communication they will try to find out the possibilities of unanimity.

\section{CONCLUSION}

The ecology of institutional and non-institutional discourse is manifested in the specificity of sphere of communication and goals, which are decisive factors that differentiate status-oriented and personality-oriented contacts and affect the norms of behavior and choice of the most effective linguistic means for a particular discursive situation. Various means of implementing speech etiquette are used to establish, maintain and close speech contact for the effectiveness of communication. Contacts in non-institutional discourse are characterized by such specific features as: informality, creativity, expressiveness and originality of speech, lack of rigid script or code and stylistically reduced register of communication, which aims to address issues of everyday life. The ecological norms of contact in Englishlanguage institutional discourse are in avoidance of imperatives, rudeness and offensive situations. A tactful attitude to the interlocutor in order to prevent insults as a guarantee of the ecology of contact in English-language discourse forms not only the foundation of the information-regulatory competence and communicative norm, but also the national value of English-speaking communicants. A fully-extended ecological English-language unison contact demonstrates phatic content in the contact-establishing phase, informativeness as objectification of the topic of communication in the contact-maintenance phase, and return to phatic content in the contact-closing phase, as the topic of communication has been discussed. Adherence to the balance of informative and phatic content is a factor of optimizing communication, as the successful use of phatic utterances improves the process of transmitting cognitively meaningful information and determines the contact ecology.

In general, the variety of means of establishing, maintaining and opening contact in the institutional discourse is not so various as in non-institutional discourses, which is due to the observance of certain ecological norms of communication, traditions and rituals in English-speaking culture. Norms of the English language create the necessary ecological basis for the communication to be effective, the communicative position of the addressant in the communication process to be strong and the communicative position of the addressee not to be weakened. 
Ecological contact is a harmonious communication of speakers for the sake of a conflict-free, cooperative, coordinated interaction. Non-ecological contact, defined as a communicative failure due to situational factors or individual psychological attitude of discourse subjects, is an oppositional form of speech behavior, characterized by non-parallel, multidirectional, inconsistent actions of speakers who seek to achieve their own goal and dominate.

Thus, it can be stated that the key to an effective ecologically correct communicative contact is a harmonious dialogue, which involves: coherence of strategies and tactics of the interlocutors; mutually acceptable mode of communication; sincere interest in the subject of discussion; politeness and tact. The study of the implementation of the communicative category CONTACT in different types of English discourse complements the existing views on the phenomenon of communicative contact, and also contributes to further explorations in the framework of functional and communicative linguistics, discourse-analysis and ecological linguistics.

\section{REFERENCES}

[1] Brown, P. \& Levinson, S. (1987). Politeness! Some Universals in Language Usage. Cambridge: CUP.

[2] Cameron, D. (2015). Разговорный дискурс. Интерпретации и практики. [Conversational Discourse. Interpretations and Practices]. Kharkiv: Humanitary Centre.

[3] Goffman, E. (1981). Forms of Talk / Oxford : Oxford University Press.

[4] Griffin, W. E. B. (1991). Battleground New York: G. P. Putnam's Sons.

[5] Hitchings, H. (2013). Sorry! The English and Their Manners. Farrar, Straus and Giroux.

[6] Ivchenko, H. (2021). Comic Function in the Animated Ecodiscourse (Case Study of "Zootopia"), Theory and Practice in Language Studies, Vol. 11, No. 9, pp. 1080-1086 DOI: http://dx.doi.org/10.17507/tpls.1109.14

[7] Issers, О. (2013). Речевое воздействие. [Speech Impact]. Moscow: Flinta.

[8] Larina, T. (2009). Категория вељливости и стиль коммуникации: сопоставление английских и русских лингвокультурных традиций [Category of Politeness and Style of Communication: Comparison of English and Russian Linguistic and Cultural Traditions]. Moscow: Yazyki slavynskyh kultur.

[9] Leech, G. (1983). Principles of Pragmatics. London, N.Y.: Longman.

[10] Ovchinnikov, V. (2008). Корни дуба. [Oak Roots]. https:// royallib.com/book/ovchinnikov_vsevolod/korni_duba.html (accessed 08/11/2021).

[11] O'Connor, M. (2017). The Social Value of Small Talk. Huffpost. https://www.huffpost.com/entry/the-social-value-of-smalltalk_b_9319842 (accessed 08/11/2021).

[12] Petrella, K. (2011). Royal Wisdom. Adamsmedia. Avon, Massachusetts.

[13] Robinson, L, Segal, J. \& Smith, M. (2015). Effective Communication: Improving Communication Skills in Your Work and Personal Relationships. https://pdresources.wordpress.com/2015/09/18/improving-communication-skills-in-your-work-andpersonal-relationships/ (accessed 08/11/2021).

[14] Samokhina, V. O. (2012). Жарт у сучасному комунікативному просторі Великої Британії та США: монографія [Јоkе in the modern communicative space of Great Britain and the United States: monograph]. View. 2nd, ref. i add. Kharkiv: V. N. Karazin Kharkiv National University.

[15] Samokhina, V. O. \& Shpak, O.V. (2019). Екологія контакту в англомовному дискурсі: монографія [Ecology of Contact in English Discourse: monograph]. Kharkiv: V. N. Karazin Kharkiv National University.

[16] Stibbe, A. (2015). Ecolinguistics: Language, Ecology and the Stories We Live By. London and New York: Routledge.

[17] Shakhovskyi, V. I. (2015). Голос эмоций в языковом круге homo sentiens [The voice of emotions in the linguistic circle of homo sentiens]. Moscow. Knizhniy dom "Librokom".

[18] UDEL - The Universal Dictionary of the English language. (1958). Ed. by H.C. Wyld. London : RKP, s.a.

[19] WNWD - Webster's New World Dictionary of American English. (1993). Ed. in Chief Victoria Neufeldt. USA : Macmillan.

[20] Worth, J. (2002). Call the Midwife. Orion Books LTD, London.

Victoria Samokhina was born in Kharkiv, Ukraine. She graduated from Kharkiv National University (Ukraine), English Philology Department in 1981. She is currently a Doctor of Philology, professor, head of the English Philology Chair, School of Foreign Languages at V. N. Karazin Kharkiv National University (Ukraine). The main research interests include ecolinguistics, discourse studies, thory of intertextuality, text linguistics.

Olena Shpak was born in Kharkiv, Ukraine. She graduated from Kharkiv National University (Ukraine), English Philology Department in 1987. She is currently a PhD assistant professor at the English Philology Department, School of Foreign Languages at V. N. Karazin Kharkiv National University (Ukraine). The main research interests include ecolinguistics and discourse analysis.

Valentina Pasynok was born in Kharkiv, Ukraine. She graduated from Kharkiv National University (Ukraine), French Philology Department in 1971. She is currently a Doctor of Pedagogical Science, professor, dean of the School of Foreign Languages at V. N. Karazin Kharkiv National University (Ukraine). The main research interests include ecolinguistics and pedagogics. 